\title{
Nitric oxide-induced calcium release: activation of type 1 ryanodine receptor, a calcium release channel, through non-enzymatic post-translational modification by nitric oxide
}

\author{
Sho Kakizawa* \\ Department of Biological Chemistry, Graduate School of Pharmaceutical Sciences, Kyoto University, Kyoto, Japan
}

\section{Edited by:}

Hiroyuki Kaiya, National Cerebral and Cardiovascular Center Research

Institute, Japan

Reviewed by:

Nilkantha Sen, Georgia Regents University, USA

Shigeki Moriguchi, Tohoku University, Japan

\section{*Correspondence:}

Sho Kakizawa, Department of Biological Chemistry, Graduate

School of Pharmaceutical Sciences, Kyoto University, 46-29

Yoshida-Shimoadachi-cho, Sakyo-ku, Kyoto 606-8501, Japan

e-mail: sho-kaki@pharm.kyoto-u.ac.jp
Nitric oxide (NO) is a typical gaseous messenger involved in a wide range of biological processes. In our classical knowledge, effects of NO are largely achieved by activation of soluble guanylyl cyclase to form cyclic guanosine-3', 5'-monophosphate. However, emerging evidences have suggested another signaling mechanism mediated by NO: "S-nitrosylation" of target proteins. S-nitrosylation is a covalent addition of an NO group to a cysteine thiol/sulfhydryl (RSH), and categorized into non-enzymatic post-translational modification (PTM) of proteins, contrasted to enzymatic PTM of proteins, such as phosphorylation mediated by various protein kinases. Very recently, we found novel intracellular calcium $\left(\mathrm{Ca}^{2+}\right)$ mobilizing mechanism, NO-induced $\mathrm{Ca}^{2+}$ release (NICR) in cerebellar Purkinje cells. NICR is mediated by type 1 ryanodine receptor (RyR1), a $\mathrm{Ca}^{2+}$ release channel expressed in endoplasmic-reticular membrane. Furthermore, NICR is indicated to be dependent on S-nitrosylation of RyR1, and involved in synaptic plasticity in the cerebellum. In this review, molecular mechanisms and functional significance of NICR, as well as non-enzymatic PTM of proteins by gaseous signals, are described.

Keywords: gaseous messenger, post-translational modification, nitric oxide, ryanodine receptor, S-nitrosylation, calcium release, synaptic plasticity, Purkinje cell

\section{INTRODUCTION}

Primary structure of proteins obtained from genome analysis is not sufficient to explain their various biological functions: while it is estimated that the human genome, for example, comprises $\sim 27,000$ genes, the total number of proteins in the human proteome is estimated at over one million. In addition to changes at the transcriptional and mRNA levels, it is now increasingly recognized that "post-translational modification (PTM) of proteins" provide important roles in a wide range of signaling pathways, including intercellular signaling pathways such as endocrine systems as well as intracellular pathways. PTMs are covalent processing events that change the properties of a protein by proteolytic cleavage or by addition of a modifying group to one or more amino acids. PTMs of proteins are indicated to be involved in various biological events through changes in protein activity, their cellular locations and dynamic interactions with other proteins $(1,2)$.

More than 300 different types of PTMs are currently known, and new ones are regularly discovered (3). In general, PTMs are categorized into two groups: enzymatic modification and nonenzymatic modification. Enzymatic PTM, including phosphorylation, acetylation, glycosylation, and lipidation, are demonstrated to be involved in a wide range of physiological and pathophysiological events in eukaryotic cellular systems. On the other hand, accumulation of products derived from non-enzymatic PTM is seen in various tissues of metabolic and age-related diseases such as Alzheimer's disease, Parkinson's disease, cataractogenesis, atherosclerosis, diabetic secondary complications, etc. (4-7). Consequently, it is thought that these accumulations are possibly causative to age-related pathology, and non-enzymatically modified proteins are considered to be useful biomarkers for these diseases $(8,9)$.

However, recent studies indicate that non-enzymatic PTM of proteins is also associated with physiological events. For example, S-nitrosylation by nitric oxide (NO) is now well established as a major source of NO bioactivity (10-12), and proteins shown to be modified in situ by S-nitrosylation (SNO-proteins) participate in a wide range of biological process including those involved in cellular trafficking (13), muscle contractility (14), apoptosis $(15,16)$, and circulation (17). In addition to non-enzymatic PTMs by reducing molecules, such as glycation by glucose, nonenzymatic modification by gaseous messengers is now attracting much attention.

\section{POST-TRANSLATIONAL MODIFICATION BY GASEOUS MESSENGERS}

A gas is a state of matter different from either the liquid or solid states. Gases possess the ability to diffuse readily in different materials and distribute uniformly within a defined space. Biological gases are assumed to diffuse freely across biologic membranes (18). Thus, gases do not bind to cell surface receptors, and do not require the intermediation of conventional membrane receptors and second messenger machinery such as G-proteins and adenylyl cyclase 
(19). Instead, the gases directly interact with targets, such as guanylyl cyclase (20). In addition to the reactions with metal centers of metalloproteins (e.g., hemoglobin), significant proportion of the direct action of gaseous messengers is mediated through nonenzymatic PTM of proteins, such as S-nitrosylation by $\mathrm{NO}$ and sulfhydration of hydrogen sulfide $\left(\mathrm{H}_{2} \mathrm{~S}\right)$ (21-23).

Probably most prevalent is the "S-nitrosylation" by NO. NO is produced enzymatically in cells expressing NO synthase (NOS) (19). Addition of NO group to the thiol side chain of cysteine residues within proteins and peptides is termed S-nitrosylation. Furthermore, peroxynitrite, produced by the reaction of NO with superoxide, is demonstrated to regulate cellular signaling (24). Peroxynitrite reacts with several amino acids. Cysteine, methionine, and tryptophan react directly, whereas tyrosine, phenylalanine, and histidine are modified through intermediary secondary species (25). Therefore, emerging evidence have indicated that non-enzymatic PTM of proteins by gaseous messengers is involved in physiological and pathological events in various biological systems (26).

\section{FUNCTIONAL MODIFICATION OF RYANODINE RECEPTORS BY S-NITROSYLATION}

Skeletal and cardiac muscles mainly express neuronal NOS (nNOS) and endothelial NOS (eNOS), respectively $(27,28)$, and endogenously produced NO can promote two physiological functions of these muscles. The first is to induce relaxation through the cGMP signaling pathway $(29,30)$. The second is to modulate increases in contraction that are dependent on reactive oxygen intermediates and independent on cGMP (27). Stoyanovsky et al. (31) thus examined effects of NO-related compounds on $\mathrm{Ca}^{2+}$ release from sarcoplasmic reticulum (SR) isolated from skeletal and cardiac muscles (31). The compounds, such as $S$-nitrosocysteine (cysNO), $S$-nitroso- $N$-acetylpenicillamine (SNAP), and S-nitrosylated glutathione (GSNO), induced $\mathrm{Ca}^{2+}$ release from the isolated SR vesicles. Correspondingly, application of SNAP increased open probability of SR channels in lipid bilayer (31). The effects of NO-related compounds on the activity of $\mathrm{Ca}^{2+}$ release channels were observed in subsequent study: Xu et al. (14) showed that GSNO and cysNO increased open probability of cardiac $\mathrm{Ca}^{2+}$ release channel in lipid bilayer (14). In this study, the rise in open probability of cardiac $\mathrm{Ca}^{2+}$ release channel was accompanied with the increased amount of $S$-nitrosothiol group per channel protein, the result suggesting the activation of cardiac $\mathrm{Ca}^{2+}$ release channels by S-nitrosylation (14). However, as is demonstrated later, $\mathrm{NO}$ or 1-hydroxy-2-oxo-3-(N-ethyl-2aminoethyl)-3-ethyl-1-triazene (NOC12) (an NO donor) do not activate or S-nitrosylate RyR2 while GSNO induce activation and S-nitrosylation of RyR2 (32). Thus, at that time, cardiac $\mathrm{Ca}^{2+}$ release channels, possibly RyR2, was suggested to be activated by GSNO-induced S-nitrosylation of the channel (14).

Subsequently, NO-induced S-nitrosylation of skeletal $\mathrm{Ca}^{2+}$ release channel was demonstrated. In these studies, $\mathrm{NO}$-sensitivity of the channels had been studied extensively in ambient $\mathrm{O}_{2}$ tension ( $\mathrm{pO}_{2} \sim 150 \mathrm{mmHg}$ ), whereas tissue $\mathrm{pO}_{2}$ is $\sim 10-20 \mathrm{mmHg}$ and even lower in exercising muscle $(33,34)$. Eu et al. (35) showed that $\mathrm{Ca}^{2+}$ release channel in SR isolated from skeletal muscle, possibly type 1 ryanodine receptor (RyR1), was activated and S-nitrosylated by submicromolar concentration of NO (35). This modification of the channel was induced restrictedly in the case that $\mathrm{pO}_{2}$ was at tissue level $(\sim 10 \mathrm{mmHg})$ but not at ambient level $(\sim 150 \mathrm{mmHg})$. However, when the concentration of $\mathrm{NO}$ was increased to micromolar ranges, the channels were activated by $\mathrm{NO}$ even in the ambient $\mathrm{O}_{2}$ levels (35). Moreover, unlike the case in $\mathrm{NO}$, activation of the channels by NOC12 or GSNO was indicated to be insensitive to $\mathrm{pO}_{2}$ levels: $\mathrm{NOC12}$ and GSNO activated skeletal $\mathrm{Ca}^{2+}$ channels in SR at ambient $\mathrm{O}_{2}$ levels even when the concentration of these compounds were low enough and the estimated levels of $\mathrm{NO}$ produced from these compounds were submicromolar ranges (36).

Eu et al. (35) also estimated that only one cysteine in RyR1 was S-nitrosylated by submicromolar concentrations of NO at tissue $\mathrm{O}_{2}$ level (35). Subsequently, the target of S-nitrosylation was identified as Cys3635: single-cite C3635A-mutaion in RyR1 abolished NO-induced S-nitrosylation of the mutated channels expressed in HEK 293 cells (37). In addition, the NO-induced rise in open probability was abolished in the C3635A-mutant channels in lipid bilayer (36). C3635 is intercalated within the hydrophobic calmodulin (CaM)-binding domain of RyR1, and thereby S-nitrosylation of C3635 is thought to reverse channel inhibition by CaM (3840). Furthermore, C3635 was indicated to be not required for the activation of the channel by GSNO (36). Taken together, these observations suggest that NO, NOC12, and GSNO activate the redox-sensitive RyR1 channel by different mechanisms, and the effect of $\mathrm{O}_{2}$ tension on S-nitrosylation by $\mathrm{NO}$ is best rationalized by an allosteric mechanism (36).

It is also demonstrated that RyR2 is not activated by NO and the response of RyR3 to NO is much smaller than that of RyR1 (32, 41). Because the important cysteine (i.e., C3635 of rabbit RyR1) is conserved among all RyR subtypes, the three-dimensional structure around the critical cysteine residue may be important for the subtype specificity of S-nitrosylation or channel gating. However, this mechanism requires further clarification.

\section{BIOLOGICAL FUNCTION OF RyR1}

Type 1 ryanodine receptor is an intracellular calcium release channel involved in regulation of cytosolic calcium levels. The highest levels of RyR1 expression are observed in skeletal muscle, and significantly higher levels of RyR1 mRNA are seen in the esophagus and testis, when compared to other tissues (42). In addition, lower amount are found in the spleen, gut kidney, stomach, submaxillary gland, thymus, adrenal gland, and ovary. In mammalian brain, RyR1 mRNA is prominent in the cerebellar Purkinje cell (PC) layer and dentate dyrus in the hippocampal region (43). It is well known that RyR1 is essential for contraction of skeletal muscles. However, the function of RyR1 has yet to be clarified in the other tissues, because the mutant deficient in RyR1 gene shows postnatal lethality (44). Furthermore, RyR1 is demonstrated to be physiologically regulated by protein-protein interaction to voltage-gated calcium channels in skeletal muscle cells (45). Although RyR1 is also expressed in the brain, as is described above, such tight $\mathrm{Ca}^{2+}$ channel-mediated regulation of intracellular $\mathrm{Ca}^{2+}$ release through RyR1, as seen in skeletal muscle cells, is absent in central neurons (46). Therefore, further study into the regulatory mechanisms and functions of RyR1 in the brain is warranted. 


\section{NO-INDUCED $\mathrm{Ca}^{2+}$ RELEASE INDUCED BY NEURONAL ACTIVITY}

As is described so far, the redox regulation of RyRs were extensively studied using in vitro experimental systems, especially in lipid bilayer and SR isolated from skeletal and cardiac muscles. On the other hand, involvement of S-nitrosylation of RyR in $\mathrm{Ca}^{2+}$ release in living cells and physiological function of the channel modulation by endogenous NO have yet to be demonstrated, although increased open probability of RyR1 by S-nitrosylation was suggested to enhance $\mathrm{Ca}^{2+}$ leakage from skeletal muscle $\mathrm{Ca}^{2+}$ stores (SR) under pathological conditions $(47,48)$.

Involvement of S-nitrosylation in neuronal function has been suggested in the cerebellar cortex. PCs, the principal and solely output neurons in the cerebellar cortex, receive two types of excitatory (glutamatergic) inputs: climbing fiber, originate from inferior olive, and parallel fiber (PF), axon of cerebellar granule cells (49). The PF-to-PC synapse (PF synapse) is extensively studied, because many studies indicate that long-term depression (LTD), a kind of synaptic plasticity, of PF synapse is a cellular basis for the cerebellar-dependent learning such as eyeblink conditioning (49-51). In addition to LTD, long-term potentiation (LTP) is observed in PF synapse (PF-LTP). When PF are repeatedly stimulated, the current response of PF synapse is potentiated for $30 \mathrm{~min}$, at least. Three groups demonstrated that the PF-LTP is dependent on NO signals (52-54). Furthermore, although the protocol (the stimulus pattern) for the LTP induction are slightly different between Lev-Ram et al. (53) and Namiki et al. (54), both groups demonstrated that this NO-dependent LTP is insensitive to $1 \mathrm{H}$-[1,2,4] oxadiazolo[4,3-a] quinoxalin-1-one (ODQ), a selective inhibitor of sGC activation by $\mathrm{NO}(53,54)$. Thus, PF-LTP is indicated to be dependent on signaling pathways mediated by S-nitrosylation. Furthermore, in their preliminary experiments, Kakizawa et al. observed that PF-LTP was dependent also on intracellular $\mathrm{Ca}^{2+}$ signals. Taken together, PF-LTP was indicated to be dependent on $\mathrm{S}$-nitrosylation and $\mathrm{Ca}^{2+}$ signals, and these results lead to our hypothesis: S-nitrosylation-mediated $\mathrm{Ca}^{2+}$ release is induced by PF activity and involved in the induction of PF-LTP.

First, Kakizawa et al. (41) demonstrated that bath application of 1-hydroxy-2-oxo-3-( $N$-methyl-3-aminopropyl)-3-methyl-1triazene (NOC7), an NO donor, induced $\mathrm{Ca}^{2+}$ elevation in cerebellar PC in acute slice preparation from young-adult (1- to 2 -month-old) mice (41). Subsequently, this NO-induced $\mathrm{Ca}^{2+}$ elevation was revealed to be $\mathrm{Ca}^{2+}$ release mediated by RyR1: the $\mathrm{NO}$-induced $\mathrm{Ca}^{2+}$ increase was abolished by thapsigargin, cyclopiazonic acid (CPA) [inhibitors of sarco/endoplasmic-reticulum $\mathrm{Ca}^{2+}$ ATPase (SERCA)], and dantrolene (a specific inhibitor for RyR1), but insensitive to chelating the extracellular $\mathrm{Ca}^{2+}$ and heparin (a specific inhibitor for $\mathrm{IP}_{3} \mathrm{Rs}$ ) (Figure 1). Involvement of RyR1 was further confirmed by impaired $\mathrm{NO}$-induced $\mathrm{Ca}^{2+}$ elevation in PCs in RyR1-knockout mice (44). Moreover, RyR1 was indicated to be necessary and sufficient for $\mathrm{NO}$-induced $\mathrm{Ca}^{2+}$ increase by the experiment using HEK 293 cells, expressing little endogenous RyRs: $\mathrm{NO}$-induced $\mathrm{Ca}^{2+}$ elevation was observed only in the cells expressing exogenous RyR1, identified by $\mathrm{Ca}^{2+}$ response to caffeine, a well-known agonist of RyRs. Furthermore, NO-induced $\mathrm{Ca}^{2+}$ increase was indicated to be insensitive to ODQ, a sGC inhibitor. The result suggested that the $\mathrm{Ca}^{2+}$ increase

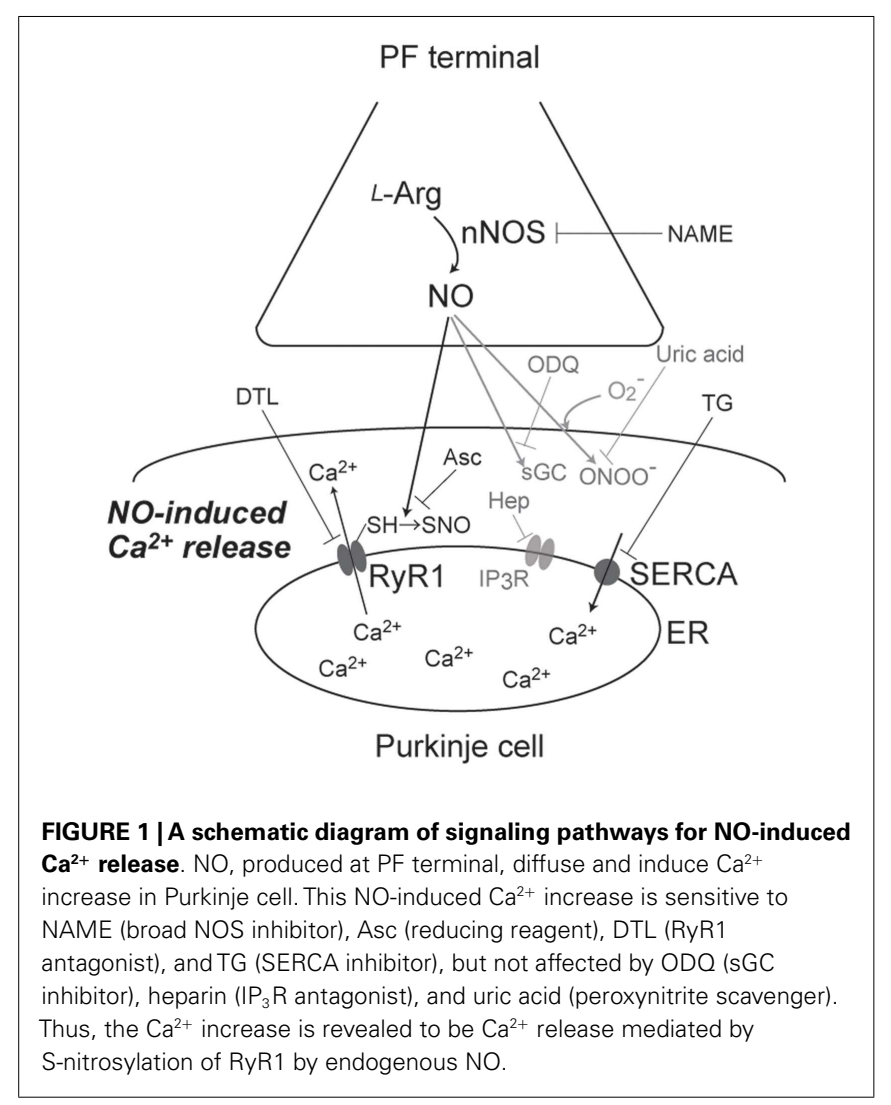

is independent on sGC-mediated pathways, including activation of RyRs by cyclic ADP ribose, whose formation is induced by cGMP (55). Instead, the result indirectly suggested that NOinduced $\mathrm{Ca}^{2+}$ increase is dependent on S-nitrosylation of proteins (Figure 1). Correspondingly, biochemical analysis indicated that $\mathrm{NO}$-induced $\mathrm{Ca}^{2+}$ elevation was accompanied with the transient increase in S-nitrosylation levels of endogenous RyR1 in cerebellar slices. NO-induced increase in S-nitrosylation level was also observed in exogenous RyR1 expressed in HEK cells. Thus, NOinduced $\mathrm{Ca}^{2+}$ elevation was revealed to be $\mathrm{Ca}^{2+}$ release mediated by RyR1 (Figure 1), and was named "NO-induced $\mathrm{Ca}^{2+}$ release (NICR)" (41).

Subsequently, Kakizawa et al. (41) examined induction of NICR by physiological patterns of neuronal activity. When the burst stimulus (BS) inducing PF-LTP was applied to PF, $\mathrm{Ca}^{2+}$ levels in $\mathrm{PCs}$ were transiently but clearly elevated. This $\mathrm{BS}$-induced $\mathrm{Ca}^{2+}$ increase was indicated to be $\mathrm{Ca}^{2+}$ release mediated by RyR1, because the $\mathrm{Ca}^{2+}$ increase was abolished by bath application of thapsigargin, CPA, and dantrolene. Furthermore, BS-induced $\mathrm{Ca}^{2+}$ elevation was inhibited by NG-nitro-L-arginine methyl ester (L-NAME), a broad antagonist of NOSs, and abolished also in nNOS-knockout mice (56). Taken together, BS-induced $\mathrm{Ca}^{2+}$ elevation was revealed to be dependent on both $\mathrm{NO}$ signals and $\mathrm{Ca}^{2+}$ release through RyR1 (Figure 1). Thus, BS-induced $\mathrm{Ca}^{2+}$ increase is indicated to be NICR, and NICR is demonstrated to be induced by physiological patterns of neuronal activity.

Neuronal activity in conjunction with certain forms of synaptic plasticity may be associated with superoxide generation, and NO 
generation leads to peroxynitrite formation when superoxide is simultaneously generated $(57,58)$. Because peroxynitrite is known to regulate cell signaling via molecular modifications, including protein nitration $(57,58)$, it seems possible that NICR is affected by peroxynitrite produced from endogenous $\mathrm{NO}$ in the presence of superoxide. Therefore, Kakizawa et al. (59) examined the potential role of peroxynitrite in the BS-induced $\mathrm{Ca}^{2+}$ release and LTP (59). Bath application of the peroxynitrite scavenger, uric acid, and the peroxynitrite decomposition catalyst, 5,10,15,20-tetrakis(4sulfonatophenyl)porphyrinato iron(III) (FeTPPS), had no effect on BS-induced $\mathrm{Ca}^{2+}$ increase), although the concentration of uric acid $(100 \mu \mathrm{M})$ and FeTPPS $(10 \mu \mathrm{M})$ were thought to be high enough. In accordance with the insensitivity of NICR to these reagents, neither uric acid nor FeTPPs impaired the induction of PF-LTP induced by BS. These results do not support the involvement of peroxynitrite in NICR and PF-LTP induction, and NICR is indicated to by induced directly by endogenous NO (Figure 1).

\section{PHYSIOLOGICAL FUNCTION OF NICR}

Because the BS, which induces NICR, has been already indicated to induce PF-LTP (54), it is strongly suggested that NICR is involved in the induction of PF-LTP. Actually, all manipulations that inhibit NICR (application of L-NAME, thapsigargin, and dantrolene; see also Figure 1) abolished PF-LTP in PCs. In addition, neither PF-LTP nor NICR was induced in the cerebellum of nNOS-knockout mice. Furthermore, both PF-LTP and NICR were inhibited by intracellular application of ascorbic acid from patch pipette (Figure 1). Because ascorbic acid is a reducing agent, the results also support the idea that S-nitrosylation is required for the induction of NICR as well as PF-LTP. On the other hand, bath application of uric acid, a scavenger of peroxynitrite $\left(\mathrm{ONOO}^{-}\right.$, produced by reaction of $\mathrm{NO}$ with superoxide), or pipette application of heparin inhibited neither NICR nor PF-LTP. Taken together, NICR is revealed to be induced by physiological activity of PF and essential for the induction of PF-LTP, and these observations strongly indicate that $\mathrm{Ca}^{2+}$ release mediated by S-nitrosylation of RyR1 is induced in living cells and has physiological function(s) (41) (Figure 1).

\section{PERSPECTIVES: POSSIBLE INDUCTION AND PHYSIOLOGICAL FUNCTION OF NICR IN VIVO}

In the study by Kakizawa et al. (41), NICR was induced by physiological patterns of neuronal activity (BS to PF) in artificial

\section{REFERENCES}

1. Mann M, Jensen ON. Proteomic analysis of posttranslational modifications. Nat Biotechnol (2003) 21:255-61. doi:10.1038/nbt0303-255

2. Seo J, Lee KJ. Post-translational modifications and their biological functions: proteomic analysis and systematic approaches. J Biochem Mol Biol (2004) 37: 35-44. doi:10.5483/BMBRep.2004. 37.1.035

3. Jensen ON. Modification-specific proteomics: characterization of post-translational modifications

cerebrospinal fluid (ACSF) bubbled with $95 \% \mathrm{O}_{2} / 5 \% \mathrm{CO}_{2}$. In the component of PF-PC synapse, expression of nNOS is observed in PFs and NO is thought to be released from PF terminal (60, 61). Thus, NO, produced at PF in response to the neuronal activity, is thought to diffuse and induce S-nitrosylation of RyR1 in PCs. As is already demonstrated by Eu et al. (35), RyR1 is Snitrosylated in the ambient $\mathrm{pO}_{2}$ levels only when the concentration of NO is micromolar level (35). Is the level of NO produced by the BS inducing NICR and PF-LTP micromolar range? Using the NO-sensitive fluorescent probe, Namiki et al. (54) estimated the BS-induced NO level in PCs in the cerebellar slice (54). The NO concentration induced by the BS was estimated to the order of $\sim 5 \mu \mathrm{M}$. Correspondingly, in the cerebellar PCs, NICR was induced when NOC7 was higher than $10 \mu \mathrm{M}$ (Kakizawa et al., unpublished data), and $10 \mu \mathrm{M}$ NOC7 is estimated to yield $\sim 1 \mu \mathrm{M}$ NO (54). Thus, NICR is suggested to be induced by physiological patterns of neuronal activity, which induces PF-LTP, through the micromolar levels of $\mathrm{NO}$ in the ambient $\mathrm{pO}_{2}$ condition. On the other hand, it is still possible that the level of NO required for the induction of NICR and PF-LTP is overestimated. because $\mathrm{pO}_{2}$ at tissue level $(\sim 10 \mathrm{mmHg})$ is much lower than the ambient level $(\sim 150 \mathrm{mmHg})$, and the submicromolar levels of NO is indicated to induce S-nitrosylation and activation of RyR1 at the tissue $\mathrm{pO}_{2}$ levels (35).

Expressions of RyR1 as well as NOS (especially nNOS) are observed in various regions of the brain $(43,60)$. Furthermore, expression of RyR1 is demonstrated in various tissues other than brain and skeletal muscles, such as digestive tissues and reproductive tissues (42). Therefore, NICR may have a wide range of physiological functions in these tissues.

\section{ACKNOWLEDGMENTS}

This work was supported by JSPS KAKENHI [Grant-in-Aid for Scientific Research on Innovative Areas (Brain Environment), Grant-in-Aid for Challenging Exploratory Research and Grantsin-Aid for Scientific Research (C)], and Grants from Narishige Neuroscience Foundation, Takeda Science Foundation, Mochida Memorial Foundation, Suzuken Memorial Foundation, and Brain Science Foundation. I also appreciate Prof. Masamitsu Iino (University of Tokyo), Prof. Nozomu Mori (Nagasaki University), and Prof. Hiroshi Takeshima (Kyoto University) for their continuous encouragements.

Gerontol (2006) 41:464-73. doi:10.1016/j.exger.2006.03.004

6. Jaisson S, Gillery P. Evaluation of nonenzymatic posttranslational modification-derived products as biomarkers of molecular aging of proteins. Clin Chem (2010) 56:1401-12. doi:10.1373/ clinchem.2010.145201

7. Jay D, Hitomi $H$, Griendling KK. Oxidative stress and diabetic cardiovascular complications. Free Radic Biol Med (2006) 40:183-92. doi:10. 1016/j.freeradbiomed.2005.06.018

8. Baynes JW. The clinical chemome: a tool for the diagnosis and management of chronic disease. Clin Chem (2004) 50: 1116-7. doi:10.1373/clinchem. 2004.034645

9. Meerwaldt R, Links T, Zeebregts C, Tio R, Hillebrands JL, Smit A. The clinical relevance of assessing advanced glycation endproducts accumulation in diabetes. Cardiovasc Diabetol (2008) 7:29. doi:10. 1186/1475-2840-7-29

10. Hess DT, Matsumoto A, Kim SO, Marshall HE, Stamler JS. Protein Snitrosylation: purview and parameters. Nat Rev Mol Cell Biol (2005) 6:150-66. doi:10.1038/nrm1569 
11. Seth D, Stamler JS. The SNOproteome: causation and classifications. Curr Opin Chem Biol (2011) 15:129-36. doi:10.1016/j. cbpa.2010.10.012

12. Shahani N, Sawa A. Nitric oxide signaling and nitrosative stress in neurons: role for Snitrosylation. Antioxid Redox Signal (2011) 14:1493-504. doi:10.1089/ars.2010.3580

13. Ozawa K, Whalen EJ, Nelson CD, $\mathrm{Mu}$ Y, Hess DT, Lefkowitz RJ, et al. S-nitrosylation of beta-arrestin regulates beta-adrenergic receptor trafficking. Mol Cell (2008) 31: 395-405. doi:10.1016/j.molcel. 2008.05.024

14. Xu L, Eu JP, Meissner G, Stamler JS. Activation of the cardiac calcium release channel (ryanodine receptor) by poly-S-nitrosylation. Science (1998) 279:234-7. doi:10.1126/ science.279.5348.234

15. Benhar M, Forrester MT, Hess DT, Stamler JS. Regulated protein denitrosylation by cytosolic and mitochondrial thioredoxins. Science (2008) 320:1050-4. doi:10. 1126/science. 1158265

16. Cho DH, Nakamura T, Fang J, Cieplak P, Godzik A, Gu Z, et al. S-nitrosylation of Drpl mediates beta-amyloid-related mitochondrial fission and neuronal injury. Science (2009) 324:102-5. doi:10.1126/ science.1171091

17. Singel DJ, Stamler JS. Chemical physiology of blood flow regulation by red blood cells: the role of nitric oxide and Snitrosohemoglobin. Annu Rev Physiol (2005) 67:99-145. doi:10.1146/ annurev.physiol.67.060603.090918

18. Kajimura M, Fukuda R, Bateman RM, Yamamoto T, Suematsu M. Interactions of multiple gastransducing systems: hallmarks and uncertainties of $\mathrm{CO}, \mathrm{NO}$, and $\mathrm{H} 2 \mathrm{~S}$ gas biology. Antioxid Redox Signal (2010) 13:157-92. doi:10.1089/ars. 2009.2657

19. Sen N, Snyder SH. Protein modifications involved in neurotransmitter and gasotransmitter signaling. Trends Neurosci (2010) 33: 493-502. doi:10.1016/j.tins.2010. 07.004

20. Garthwaite J. New insight into the functioning of nitric oxide-receptive guanylyl cyclase: physiological and pharmacological implications. Mol Cell Biochem (2010) 334:221-32. doi:10.1007/s11010-009-0318-8

21. Kimura H. Hydrogen sulfide: from brain to gut. Antioxid Redox Signal (2010) 12:1111-23.
22. Mustafa AK, Gadalla MM, Sen $\mathrm{N}$, Kim S, Mu W, Gazi SK, et al. H2S signals through protein S-sulfhydration. $\mathrm{Sci}$ Signal (2009) 2(96):ra72. doi:10.1126/scisignal.2000464

23. Paul BD, Snyder SH. H2S signalling through protein sulfhydration and beyond. Nat Rev Mol Cell Biol (2012) 13:499-507. doi:10. 1038/nrm3391

24. Szabo C, Ischiropoulos H, Radi R. Peroxynitrite: biochemistry, pathophysiology and development of therapeutics. Nat Rev Drug Discov (2007) 6:662-80. doi:10.1038/ $\operatorname{nrd} 2222$

25. Abello N, Kerstjens HAM, Postma DS, Bischoff R. Protein tyrosine nitration: selectivity, physicochemical and biological consequences, denitration, and proteomics methods for the identification of tyrosine-nitrated proteins. J Proteome Res (2009) 8:3222-38. doi:10.1021/pr900039c

26. Kajimura $M$, Nakanishi $T$, Takenouchi T, Morikawa T, Hishiki T, Yukutake $\mathrm{Y}$, et al. Gas biology: tiny molecules controlling metabolic systems. Respir Physiol Neurobiol (2012) 184:139-48. doi:10. 1016/j.resp.2012.03.016

27. Kobzik L, Reid MB, Bredt DS, Stamler JS. Nitric-oxide in skeletalmuscle. Nature (1994) 372:546-8. doi:10.1038/372546a0

28. Sartoretto JL, Kalwa H, Pluth MD, Lippard SJ, Michel T. Hydrogen peroxide differentially modulates cardiac myocyte nitric oxide synthesis. Proc Natl Acad Sci U S A (2011) 108:15792-7. doi:10.1073/ pnas.1111331108

29. Balligand JL, Kelly RA, Marsden PA, Smith TW, Michel T. Control of cardiac-muscle cell-function by an endogenous nitric-oxide signaling system. Proc Natl Acad Sci U $S$ A (1993) 90:347-51. doi:10.1073/ pnas.90.1.347

30. Mohan P, Brutsaert DL, Paulus WJ, Sys SU. Myocardial contractile response to nitric oxide and cGMP. Circulation (1996) 93: 1223-9. doi:10.1161/01.CIR.93.6. 1223

31. Stoyanovsky D, Murphy T, Anno PR, Kim YM, Salama G. Nitric oxide activates skeletal and cardiac ryanodine receptors. Cell Calcium (1997) 21:19-29. doi:10.1016/ S0143-4160(97)90093-2

32. Sun J, Yamaguchi N, Xu L, Eu JP, Stamler JS, Meissner G. Regulation of the cardiac muscle ryanodine receptor by $\mathrm{O}(2)$ tension and S-nitrosoglutathione. Biochemistry
(2008) 47:13985-90. doi:10.1021/ bi8012627

33. Gorczynski RJ, Duling BR. Role of oxygen in arteriolar functional vasodilation in hamster striatedmuscle. Am J Physiol (1978) 235:H505-15.

34. Honig CR, Gayeski TEJ. Resistance to $\mathrm{O} 2$ diffusion in anemic red muscle: roles of flux-density and cell PO2. Am J Physiol (1993) 265:H868-75.

35. Eu JP, Sun JH, Xu L, Stamler JS, Meissner G. The skeletal muscle calcium release channel: coupled O2 sensor and NO signaling functions. Cell (2000) 102:499-509. doi:10. 1016/S0092-8674(00)00054-4

36. Sun JH, Xu L, Eu JP, Stamler JS, Meissner G. Nitric oxide, NOC12 , and S-nitrosoglutathione modulate the skeletal muscle calcium release channel/ryanodine receptor by different mechanisms - an allosteric function for $\mathrm{O} 2$ in $\mathrm{S}$ nitrosylation of the channel. J Bio Chem (2003) 278:8184-9. doi:10. 1074/jbc.M211940200

37. Sun JH, Xin CL, Eu JP, Stamler JS, Meissner G. Cysteine-3635 is responsible for skeletal muscle ryanodine receptor modulation by NO. Proc Natl Acad Sci U S A (2001) 98:11158-62. doi:10.1073/ pnas. 201289098

38. Hess DT, Matsumoto A, Nudelman R, Stamler JS. S-nitrosylation: spectrum and specificity. Nat Cell Biol (2001) 3:E46-9. doi:10.1038/ 35055152

39. Lanner JT, Georgiou DK, Joshi AD, Hamilton SL. Ryanodine receptors: structure, expression, molecular details, and function in calcium release. Cold Spring Harb Perspect Biol (2010) 2(11):a003996. doi:10. 1101/cshperspect.a003996

40. Moore CP, Zhang JZ, Hamilton SL. A role for cysteine 3635 for RYR1 in redox modulation and calmodulin binding. J Biol Chem (1999) 274:36831-4. doi:10.1074/ jbc.274.52.36831

41. Kakizawa S, Yamazawa T, Chen Y, Ito A, Murayama $\mathrm{T}$, Oyamada $\mathrm{H}$, et al. Nitric oxide-induced calcium release via ryanodine receptors regulates neuronal function. $E M B O$ J (2012) 31:417-28. doi:10.1038/ emboj.2011.386

42. Giannini G, Conti A, Mammarella S, Scrobogna M, Sorrentino V. The ryanodine receptor calciumchannel genes are widely and differentially expressed in murine brain and peripheral-tissues. J Cell Biol (1995) 128:893-904. doi:10.1083/ jcb.128.5.893
43. Mori F, Fukaya M, Abe H, Wakabayashi K, Watanabe M. Developmental changes in expression of the three ryanodine receptor mRNAs in the mouse brain. Neurosci Lett (2000) 285: 57-60. doi:10.1016/S03043940(00)01046- 6

44. Takeshima $\mathrm{H}$, Iino $\mathrm{M}$, Takekura $\mathrm{H}$, Nishi $\mathrm{M}$, Kuno J, Minowa $\mathrm{O}$, et al. Excitation-contraction uncoupling and muscular degeneration in mice lacking functional skeletalmuscle ryanodine-receptor gene. Nature (1994) 369:556-9. doi:10. 1038/369556a0

45. Endo M. Calcium-induced calcium release in skeletal muscle. Physiol Rev (2009) 89:1153-76. doi:10. 1152/physrev.00040.2008

46. Kano M, Garaschuk O, Verkhratsky A, Konnerth A. Ryanodine receptormediated intracellular calciumrelease in rat cerebellar Purkinje neurons. J Physiol (1995) 487: $1-16$.

47. Bellinger AM, Reiken S, Carlson C, Mongillo M, Liu X, Rothman L, et al. Hypernitrosylated ryanodine receptor calcium release channels are leaky in dystrophic muscle. Nat Med (2009) 15:325-30. doi:10.1038/nm. 1916

48. Durham WJ, Aracena-Parks P, Long C, Rossi AE, Goonasekera SA, Boncompagni S, et al. RyR1 S-nitrosylation underlies environmental heat stroke and sudden death in Y522S RyR1 knockin mice. Cell (2008) 133:53-65. doi:10.1016/ j.cell.2008.02.042

49. Ito M. Cerebellar circuitry as a neuronal machine. Prog Neurobiol (2006) 78:272-303. doi:10.1016/j. pneurobio.2006.02.006

50. Ito M. Cerebellar long-term depression: characterization, signal transduction, and functional roles. Physiol Rev (2001) 81: 1143-95.

51. Ito M. The molecular organization of cerebellar long-term depression. Nat Rev Neurosci (2002) 3:896-902. doi:10.1038/nrn962

52. Kakegawa W, Yuzaki M. A mechanism underlying AMPA receptor trafficking during cerebellar long-term potentiation. Proc Natl Acad Sci U S A (2005) 102: 17846-51. doi:10.1073/pnas. 0508910102

53. Lev-Ram V, Wong ST, Storm DR, Tsien RY. A new form of cerebellar long-term potentiation is postsynaptic and depends on nitric oxide but not cAMP. Proc Natl Acad Sci U SA (2002) 99:8389-93. doi:10.1073/ pnas.122206399 
54. Namiki S, Kakizawa S, Hirose K, Iino M. NO signalling decodes frequency of neuronal activity and generates synapse-specific plasticity in mouse cerebellum. J Physiol (2005) 566:849-63. doi:10.1113/ jphysiol.2005.088799

55. Galione A. Cyclic ADP-ribose, the ADP-ribosyl cyclase pathway and calcium signaling. Mol Cell Endocrinol (1994) 98: 125-31. doi:10.1016/03037207(94)90130-9

56. Huang PL, Dawson TM, Bredt DS, Snyder SH, Fishman MC. Targeted disruption of the neuronal nitric-oxide synthase gene. Cell (1993) 75: 1273-86. doi:10.1016/00928674(93)90615-W
57. Kishida KT, Klann E. Sources and targets of reactive oxygen species in synaptic plasticity and memory. Antioxid Redox Signal (2007) 9:233-44.

58. Pacher P, Beckman JS, Liaudet L. Nitric oxide and peroxynitrite in health and disease. Physiol Rev (2007) 87:315-424. doi:10.1152/ physrev.00029.2006

59. Kakizawa S, Yamazawa T, Iino M. Nitric oxide-induced calcium release activation of type 1 ryanodine receptor by endogenous nitric oxide. Channels (2013) 7:1-5. doi:10.4161/chan. 22555

60. Bredt DS, Hwang PM, Snyder $\mathrm{SH}$. Localization of nitric-oxide synthase indicating a neural role for nitric-oxide. Nature (1990) 347:768-70. doi:10.1038/347768a0

61. Shibuki K, Kimura S. Dynamic properties of nitric oxide release from parallel fibres in rat cerebellar slices. J Physiol (1997) 498 : 443-52.

Conflict of Interest Statement: The author declares that the research was conducted in the absence of any commercial or financial relationships that could be construed as a potential conflict of interest.

Received: 03 September 2013; accepted: 25 September 2013; published online: 11 October 2013.

Citation: Kakizawa S (2013) Nitric oxide-induced calcium release: activation of type 1 ryanodine receptor, a calcium release channel, through nonenzymatic post-translational modification by nitric oxide. Front. Endocrinol. 4:142. doi: 10.3389/fendo.2013.00142 This article was submitted to Experimental Endocrinology, a section of the journal Frontiers in Endocrinology.

Copyright (c) 2013 Kakizawa. This is an open-access article distributed under the terms of the Creative Commons Attribution License (CC BY). The use, distribution or reproduction in other forums is permitted, provided the original author(s) or licensor are credited and that the original publication in this journal is cited, in accordance with accepted academic practice. No use, distribution or reproduction is permitted which does not comply with these terms. 